\title{
DEPRESSION IN A HOUSEHOLD SAMPLE IN ARACAJU (SERGIPE, BRAZIL)
}

\author{
Mariana Siqueira Menezes ${ }^{1}$ \\ André Faro \\ Federal University of Sergipe, Brazil
}

\begin{abstract}
This study aimed to detect the prevalence rate of depression-related symptoms in a household sample in Aracaju (Sergipe, Brazil), as well as estimating the chances of a positive diagnosis in the screening for depression based on socio-demographic and general health profiles. The sample was composed of 690 participants and only one resident per house was invited to take part in this study. The Beck Depression Inventory (BDI), questionnaires about socio-demographic and health-related data were used. Almost 35\% of participants had positive diagnosis in the screening for depression. A logistic regression showed that those people who perceived themselves as sick, non-religious, lacked a college degree, smokers or who were obese, smokers composed the profile of individuals with a greater chance to be in the BDI positive group. Finally, the proposed objectives to this study allowed inferring that the population living in Aracaju present a high prevalence rate of depression-related symptoms. Considering that the interviews were conducted at home, it is still possible that part of the sample that showed these symptoms may not have sought assistance at primary health centers or have been assessed by primary care team. Thus, we think these findings are important due to the lack of similar studies in Brazilian Northeast region.
\end{abstract}

\section{Keywords}

Depression; Beck Depression Inventory (BDI); Household sample; Prevalence; Social distribution.

\section{RESUMO}

Este estudo objetivou detectar a prevalência de sintomas associados à depressão em uma amostra domiciliar em Aracaju (Sergipe, Brasil), bem como estimar as chances para diagnóstico de rastreamento positivo de depressão com base nos perfis sociodemográfico e de saúde geral. Compuseram a amostra 690 participantes e apenas uma pessoa por domicílio foi convidada a fazer parte do estudo. Aplicaram-se o Inventário de Depressão de Beck (BDI) e questionários a respeito de dados sociodemográficos e de saúde. Aproximadamente $35 \%$ dos participantes tiveram diagnóstico de rastreamento positivo para a sintomatologia depressiva. A regressão logística mostrou que aqueles que se descreviam como doentes, tabagistas, os que não declararam religião, obesos e aqueles sem nível de educação superior apresentaram chances mais altas para exibir sintomatologia depressiva. Ao final, os objetivos propostos por este estudo permitiram inferir que a população de Aracaju apresenta uma alta prevalência de sintomas depressivos. Tendo em vista que as entrevistas foram feitas nos domicílios, é possível que parte da amostra não tenha procurado por assistência à saúde nas unidades básicas de saúde ou tenha sido avaliada pelas equipes da saúde primária. Portanto, entende-se que tais achados adquirem importância visto que são poucos os estudos domiciliares sobre depressão no Nordeste brasileiro.

\section{Palavras-chave}

Depressão; Beck Depression Inventory (BDI); Amostragem domiciliar; Prevalência; Distribuição social.

\footnotetext{
${ }^{1}$ Correspondence about this article should be addressed to Mariana Siqueira Menezes. Email: marianasm.psicologia@gmail.com
} 


\section{DEPRESSÃO EM UMA AMOSTRA DOMICILIAR EM ARACAJU (SERGIPE, BRASIL)}

Depression is one of the most common and recurrent psychiatric disorders. It has a high impact on the burden of mental disorders and high prevalence rates in many countries, which includes Brazil (Kessler \& Bromet, 2013; Silva, Galvão, Martins, \& Pereira, 2014). From the Global Burden of Disease study (GBD), it was found that depression has the highest impact on the burden of mental disorders and it is the third leading position of Years Lived with Disability (YLD) worldwide (Vos et al., 2016). Depressive disorders are a global public health issue and cause high socio-economic costs due to expenditures on treatment and productive deficits at individual and governmental levels (Ferrari et al., 2013; World Health Organization [WHO], 2017).

Depression is among the main reasons for withdrawal from work because of its significant level of disability. It also accounts for decreased quality of life, triggering and/or exacerbating other diseases, as well as significantly increasing the mortality risk (Kaskow et al., 2013; Kessler \& Bromet, 2013; Martínez et al, 2017; Stubbs et al., 2017). Moreover, depression is aggravated when combined with conditions of social and psychological vulnerability, such as unemployment or underemployment, poverty, conflicting family, and harmful social environments (Gonçalves et al., 2014; WHO, 2017).

In terms of definition, depression is classified as a mental disorder characterized by a set of changes in mood and psychomotricity that affect the individual's adaptive skills, and it has to be identified and treated accordingly (American Psychiatric Association [APA], 2013). Although there is a certain consistency in the global prevalence of depression, the estimates across countries vary (Ferrari et al., 2013; Kessler \& Bromet, 2013). From pre-existing data of studies in several countries, Ferrari et al. (2013) found the global prevalence of depression disorders around 6\%. In Brazil there are some population studies on depression, but they still are too few considering the dimension and diversity of the country (Silva et al., 2014). The studies that we found were Coelho et al. (2013) with data from 143 Brazilian cities $(n=3,007)$, and they identified about a third of a sample presenting significant levels of depressive symptoms. Vianna, Teixeira, Beraldi, Bassani, and Andrade (2009) found $18 \%$ as prevalence of psychiatric disorders in the metropolitan region of São Paulo. Finally, Gonçalves et al. (2014) detected the depression prevalence above $20 \%$ in four large Brazilian capitals (Porto Alegre, Rio de Janeiro, São Paulo, and Fortaleza). In a recent review of population-based crosssectional research, Silva et al. (2014) estimated the national Brazilian prevalence in 14\%.

Though Sergipe is the smallest state in Brazil, it follows the national trend of having scarce publications on depression prevalence. Among existing studies in Sergipe, the sampling designs generally consider specific groups for the analysis of depression, like fibromyalgia patients (Santos, Quintans Junior, Fraga, Macieira, \& Bonjardim, 2012). This fact is reinforced because only two prevalence studies were performed in Brazilian Northeast, which denotes lack of investigations in this region of the country (Silva et al., 2014).

In order to understand the prevalence of depression it is necessary to consider aspects related to the socio-demographic profile. The social distribution of the disorder allows the evaluation of how different strata and social groups exhibit greater or lesser vulnerability to the disease. It is known that depression rates are higher in women, from 5 to $9 \%$, while 2 to $3 \%$ in men. Throughout life span, women are $25 \%$ more likely to develop the disorder (Kessler \& Bromet, 2013; Salk, Hyde, \& Abramson, 2017; Schuch, Roest, Nolen, Penninx, \& Jonge, 2014). Studies have also shown that the incidence of depression vary according to age, income, socioeconomic status, and educational background (Baker, Leon, Greenaway, Collins, \& Movit, 2011; Bromet et al., 2011).

Facing such influence on the depressive disorders, the analysis of social distribution is a way to understand how risk and protective factors may cause variability in the incidence of depressive disorder. Additionally, it is known that Brazilians diagnosed with depression tend to use healthcare services more often and spend more time in hospitals than Brazilian with no depression diagnosis (Gonçalves et al., 2014). Likewise, depression presents closer relationship with suicide mortality and high comorbidity with other diseases (Katon, 2011; Stubbs et al., 2017). In spite of depression being considered one of the most common psychiatric disorders in Brazil, it still has not been investigated or treated as a priority in the country (Coelho et al., 2013). Thus, surveys in order to identify the prevalence and characterization of the social distribution of depression among different population groups can contribute to the development of public policies and also with programs to assist the most 
vulnerable strata to this mental disorder (Ferrari et al., 2013; Martínez et al., 2017; World Health Organization [WHO], 2013; WHO, 2017).

This study aimed to detect the prevalence rate of depression-related symptoms in a household sample from Aracaju (Sergipe, Brazil), as well as to estimate the chances of a positive diagnosis in the screening for depression based on the social distribution of sociodemographic and general health profiles.

\section{Participants}

\section{Method}

The survey was conducted in Aracaju (Sergipe, Brazil), a city of approximately 600 thousand inhabitants, with sex proportion of $53.5 \%$ for women and $46.5 \%$ for men, and almost $70 \%$ of the population aged between 19 and 60 (IBGE, 2012). It consisted of a cross-sectional population-based survey with data collection conducted in 15 districts of Aracaju. The districts included for data collection were randomly selected by conglomerate arrangement (three districts in each geographic region; North, South, Central, East, and West). The same methodology was applied for blocks and avenues in each of the districts.

Overall, 690 houses were visited, in each home only one resident per house was invited to take part in the study $(95 \%$ Confidence Interval $=3.4)$. Participants' age ranged from 18 to 65 , and gender differences were controlled (around 50\% for each gender) for each data collection period (morning, afternoon and evening), every day of the week. For every residence visited, another was skipped for next visit. The rate of refusal was below $1 \%$. No domestic employees, visitors, or people with selfdeclared disabling mental or physical disorder took part of the survey.

\section{Instruments}

Data was collected using a socio-demographic questionnaire, including gender (male and female), age (in years), family income (up to two times the minimum salary; two to four times; four to nine times; and over nine times), educational background (illiterate or writes one's own name; primary school; high school; and college), self-reported skin color (yellow; indigenous and other; white; parda/brown; and black), children (have children; and do not have children), conjugal relationship status (in a stable relationship; and not in a stable relationship), religion (have religious affiliation; and do not have religious affiliation), religiosity (from 0 - not religious at all -, to 10 points - extremely religious) and occupation (do not work or only study; and employed - including housekeeper).

Health-related issues were also included in the questionnaire to check whether the participant had some sort of diagnosed chronic illness, smoking, Body Mass Index - BMI [underweight, eutrophic, overweight and obesity (levels I, II and III)] and one's own perceived health (perceive oneself as sick or healthy in that moment). To be considered a smoker, participants should have had smoked at least one cigarette in the previous week, and this behavior should be regular. The BMI was calculated from self-reported data of personal weight and height.

Beck Depression Inventory (BDI) was used, which is comprised of 21 items to measure the presence and intensity of depression-related symptoms, also allowing its severity assessment [mild (12-19 points); moderate (20 to 35 points); and severe (36 to 63 points)] (Cunha, 2001). In this study, Cronbach's alpha of the BDI was .89 . The screening cutoff point to classify groups by amount of symptoms was the score 12, which is at least an indication of symptoms compatible to mild level of depression in BDI criteria. All instruments were applied by trained interviewers (30 minutes, on average).

\section{Data Analysis}

Analyses were conducted using the statistical package SPSS version 19. A BDI split score was considered as dependent variable $(0=$ negative/less than 12 and $1=$ positive/ 12 or more points $)$, while the independent variables included socio-demographic and health-related characteristics. Age was stratified into three levels: up to 25 years old, from 25 to 45 , and above 45 years old, and Religiosity was categorized as low (from 1 to 3 points), medium (from 4 to 7 points), and high religiosity (from 8 to 10 points). A logistic regression analysis was carried out (forward Wald stepwise) and it was estimated the odds ratios to the BDI score $(p<.05)$. All independent variables composed of more than two strata (for examples, BMI) were inserted in the model as dummy variables. 


\section{Ethical Considerations}

This study was approved by the Ethics Committee on Human Research of Federal University of Sergipe (UFS) (Registry: CAAE 0165.0.107.000-11). All participants declared their acquiescence with the research in a consent form.

\section{Results}

Data from 690 residents of Aracaju were analyzed, mean age was 34.7 years (standard deviation $[S D]=12.55)$ and $55.9 \%$ were females $(n=386)$. Age groups were $30.1 \%(n=208)$ up to $25,47.0 \%(n=324)$ from 25 to 45 and $22.9 \%(n=158)$ above 45 years old. Most part of the sample was parda/brown skin color $(55.2 \%, n=381)$, followed by black $(18.3 \%, n=126)$, white $(16.4 \%, n=$ $113)$ and indigenous, yellow, or other $(10.1 \% ; n=70)$. In terms of educational background, $11.9 \%(n$ $=82)$ were illiterate or just wrote their own names, $12.0 \%(n=83)$ had primary education, $33.8 \%(n=$ $233)$ finished high school and $42.3 \%(n=292)$ had a college degree.

Considering the family income, $24.3 \%(n=168)$ of respondents received up to two times the minimum salary, $35.2 \%(n=243)$ between two and four, $20.6 \%(n=142)$ from four to nine, and $19.9 \%(n=137)$ over nine times the minimum salary. Most participants were employed $(77.7 \% ; n=$ $536)$, whereas $22.3 \%(n=154)$ did not work or only studied. Almost $80 \%$ of respondents had no children $(76.7 \% ; n=529)$ and $52.2 \%(n=360)$ declared being in a stable marital relationship. Most of the interviewed reported to be affiliated to some religion $(85.7 \%, n=591)$, and with respect to religiosity, 30.6\% $(n=211)$ demonstrated low scores, $29 \%(n=200)$ medium, and 40.4\% $(n=279)$ showed high scores for religiosity. When asked about health, most respondents reported no chronic disease $(85.5 \% ; n=590)$, perceived themselves as healthy $(89.3 \% ; n=616)$, and they were nonsmokers $(89.6 \% ; n=618)$. As for BMI, $49.9 \%(n=344)$ were eutrophic, followed by overweight $(29.6 \% ; n=204)$, obese $(16.7 \% ; n=115)$, and underweight $(3.9 \%, n=27)$.

The average score on the BDI was $8.1(S D=8.23)$. Taking the mild depression severity as a cutoff point $(\geq 12), 34.8 \%(n=240)$ of the respondents were classified with some level of depression in BDI criteria (called here as BDI positive), with average score of 16.8 points $(S D=7.89)$, while $65.2 \%(n=450)$ were classified as no relevant symptoms of depression (BDI negative), with average scores of 3.5 points $(S D=3.01)$. Of those BDI positive, the majority of respondents presented mild depression $(74.6 \%, M=12.9, S D=2.64)$, followed by moderate $(20.8 \%, M=25.5, S D=4.55)$ and severe depression $(4.6 \% M=40.3, S D=3.19)$. Thus, the last two levels of severity (moderate and severe) accounted for $25.4 \%$ of sample.

In the evaluation of the assumptions to perform the logistic regression, we had to exclude two variables due to problems of multicollinearity with other variables (BMI = eutrophic strata and Educational level = high school strata). After such exclusion, the adjustment of the final model (Table 1) was good and predicted correctly almost $70 \%$ of the cases (Omnibus test $=58.834, p<.001$; Nagelkerke $\mathrm{R}^{2}=.113$; Hosmer and Lemeshow test $\left.=1.113, p=.892\right)$.

In the final model of the logistic regression it was found that subjects who perceived themselves as being sick had more than three times greater chance to be in the depression group, when compared to those who self-reported as healthy $(O R=3.4 ; p<.001)$. Similarly, those who said they have no religion exhibited almost twice higher risk of depression compared to those who followed some kind of religious affiliation $(O R=1.7 ; p=.016)$. In terms of educational background, those who did not have college degree $(O R=1.9 ; p<.001)$ were about two times more likely to show a BDI positive diagnostic. Smokers also were nearly two times more likely to have a positive classification for depressive symptomatology than non-smokers $(O R=1.9 ; p=.012)$. In relation to the BMI, obese people were almost twice as likely to be in BDI positive group when compared to non-obese $(O R=$ 1.6; $p=.040$ ). In short, people who perceived themselves as sick, non-religious, lacked a college degree, smokers or who were obese, smokers composed the profile of individuals with a greater chance to be in the BDI positive group. 
Table 1

Logistic Regression for Diagnostic Screening for Depression (BDI score $\geq 12$ ) in Aracaju (Sergipe, Brazil)

\begin{tabular}{clrrrrr}
\hline \multicolumn{2}{c}{ Variables } & N(690) & $\boldsymbol{F} \%$ & OR & CI 95\% & $p$ \\
\hline \multirow{2}{*}{ Perceived Health } & Sick & 74 & 10.7 & 3.4 & $2.0-5.7$ & $<.001$ \\
& Healthy & 616 & 89.3 & - & - & \\
\hline \multirow{2}{*}{ Religion } & No & 99 & 14.3 & 1.7 & $1.1-2.7$ & $<.001$ \\
& Yes & 591 & 85.7 & - & - & - \\
\hline \multirow{2}{*}{ Educational Background } & Non-college degree & 398 & 57.7 & 1.9 & $1.4-2.7$ & $<.001$ \\
& College degree & 292 & 42.3 & - & - & - \\
\hline \multirow{2}{*}{ Smoking } & Yes & 72 & 10.4 & 1.9 & $1.1-3.2$ & .012 \\
& No & 618 & 89.6 & - & - & - \\
\hline \multirow{2}{*}{ Body Mass Index } & Obese & 115 & 16.7 & 2.0 & $1.1-3.4$ & .014 \\
& Non-obese & 575 & 83.3 & - & - & - \\
\hline
\end{tabular}

Notes. $1 . n=$ number of subjects; $F \%=$ relative frequency; $O R=$ Odds Ratio $C I 95 \%=95 \%$

Confidence Interval; $p=$ Statistical Significance. 2. Omnibus Test $=58.834 ; p<.001 ;$ Nagelkerke $R^{2}=$ .113; Hosmer and Lemeshow Test $=1.113 ; p=.892$.

\section{Discussion}

The present study examined the prevalence of depressive disorder symptomatology in the population of Aracaju/SE (Brazil). Besides, the risk for depression was estimated using the sociodemographic and general health sample profiles. The main result indicated that almost $35 \%$ of participants show high amount of depressive symptoms ( $\geq 12$ points), which is elevated when compared to other Brazilian population-based studies.

The indicators obtained in Aracaju were different from those estimated by Gonçalves et al. (2014) with the Hospital Anxiety and Depression Scale (HADS) in the primary health care, which the prevalence varied from $21.4 \%$ in Porto Alegre, $25.0 \%$ in Rio de Janeiro, $25.3 \%$ in São Paulo, to $31.0 \%$ in Fortaleza. Coelho et al. (2013) evaluated levels of depression through the Portuguese Version of the Center for Epidemiologic Studies Depression scale (CESD) in 143 cities in Brazil and found 28.3\% of depressive symptoms prevalence rate. It is noteworthy to notice that the mentioned prevalence of depression found in other Brazilian cities were measured by different instruments. Then, such a difference limits a direct comparison between this and those other studies. However, it is interesting to highlight that a proportion close to $20 \%$ was common in several places, independently of the tool used. This means nearly one in five adults show at least mild level of depression related-symptoms.

Regarding the severity level of depression, mild level was most commonly manifested among participants of the BDI positive group in Aracaju (74.6\%). But, if we use the BDI cutoff $\geq 20$ points (moderate and severe levels), the positive group for depression becomes $24.5 \%$. In Brazil, we found three other investigations that used the BDI and had similar methodological design, with the cutoff $\geq$ 20 points. In the survey EPISONO the strata with BDI score $\geq 20$ reached 21.9\% in São Paulo (De Mello et al., 2013). On the other hand, Bortoluzzi, Kehrig, Loguercio, and Traebert (2011) studied the relationship between smoking and depression and found prevalence rate in at 5.2\% of the population of Joaçaba (Santa Catarina, Brazil). Finally, Wang, Andrade, and Gorenstein (2005) investigated a Chinese community in São Paulo and detected that $4.8 \%$ of individuals above 20 points. When considering the score relative to BDI moderate/severe levels for comparison, the results are quite different: two studies found prevalence rates above $20 \%$ (the current study one and EPISONO) and 
two others around 5\% (Bortoluzzi et al., 2011 and Wang et al., 2005). Thus, this discrepancy suggests that more population-based studies with the BDI in different contexts are still needed, because economic and sociocultural factors (Kessler \& Bromet, 2013) possibly have impact on the depression prevalence measured by BDI. However, even with these questions about different prevalence rates, instruments, and cutoffs, the results obtained in Aracaju may be of particular importance, since the findings not only discriminate the impact of depression in this city, but it could also work as a parameter for future researches; mainly because there are few studies about the prevalence of depression in the Brazilian Northeast region (Silva et al., 2014).

We detected that perceived health, BMI, smoking, religion, educational background, and BMI showed significant effects in the logistics regression analysis to the positive diagnosis of depression in BDI. Perceived health refers to an individual's perception and self-assessment of his/her own health condition, and it is an important indicator of general health. The way people perceive their own health depends on physical and emotional components, as well as on aspects related to well-being and satisfaction with life. Moreover, there is evidence that subjects who perceive themselves as sick often present certain clinical conditions and experience physical sensations of pain and/or discomfort. They also tend to be diagnosed as being sick when a clinical evaluation is performed (Boot, Koppes, Van den Bossche, Anema, \& Van der Beek, 2011).

In this investigation people who perceived themselves as sick were at least three times more likely to have depression. Generally, depressed people perceive their health as poor and are prone to self-evaluate as being sick due to the symptoms and losses derived from the depressive disorder (Boot et al., 2011). Consequently, the question of whether one sees him/herself as being health or not is a simple aspecto. Therefore, it is interesting to recommend, for example, the inclusion of this question in screenings of depression in primary healthcare.

Participants who have not declared religion were around twice more likely to compose the positive diagnostic group than those who professed any religion. Likewise, individuals with low levels of religiosity were almost two times more likely to have depression than people at high religiosity strata. Bearing this in mind, it is known that people who experience high levels of religiosity tend to declare less commonly depressive symptoms, while people with low level of religiosity, or those who have no religion at all, seem to be more vulnerable to this disorder (Moreira-Almeida, Koenig, \& Lucchetti, 2014).

The findings of this study showed that the probability to exhibit higher quantities of symptoms in participants who did not have college degree was two times greater than those who did not have. The data fit with previous research that pointed to an association between depression and education levels. Results most frequently found higher depression rates among people with lower levels of education (Bromet et al., 2011; Coelho et al., 2013). The effects of education are considered cumulative, which that means to say: the higher the level of schooling, the lower the risk of developing depressive disorder (Bromet et al., 2011). Individuals with higher education are rather inclined to allocate more resources on health, they are more motivated to reduce harmful activities to their own health, are better equipped to access health-related information and services, and also hold a sense of control over their lives, which can lead to better health outcomes (Baker et al., 2011). Education can also contribute to the individual's psychological development through self-efficacy, increase psychological resistance, and improve coping mechanisms (Feinstein, Sabates, Anderson, Sorhaindo, \& Hammond, 2006). Additionally, Coelho et al. (2013) revealed higher prevalence of depressive symptomatology in Brazilians with low educational levels rates reaching 34.4\%, while individuals who had high school levels of education or higher (complete or incomplete) had a prevalence of $24.5 \%$ and $15 \%$, respectively. Considering our results from Aracaju, the relationship between higher education and lower chances for depression was reinforced.

There is reiterated evidence of the association between smoking with psychiatric disorders, which includes depression (Figueiró et al., 2013; Mathew, Hogarth, Leventhal, Cook, \& Hitsman, 2017). In a recent meta-analysis, Luger, Suls, and Weg (2014) stated that the association between depression and smoking is frequent, with smokers exhibiting higher chances for such disorder. Like we found in Aracaju (twice more common), Bortoluzzi et al. (2011), in Joaçaba, (Santa Catarina, Brazil), detected that smokers had 2.9 times higher chances to present more depressive symptoms than nonsmokers. Bortoluzzi et al. research's had a similar design with this study (conglomerate, population, and household sample) and also used the BDI, but the main difference was the cutoff 
applied-for BDI analyses: here it was $\geq 12$ points (at least mild level) and they used $\geq 20$ points (at least moderate level). Some studies suggest that smoking and depression influence one another, and depressed people tend to smoke to relieve symptoms and feelings of sadness or negative affect (Jamal, Van der Does, Cuijpers, \& Pennix, 2012). In such cases, the smoker tends to consume nicotine as an attempt to decrease the negative effects of depressive symptoms, because the substance may provide some reduction of tension symptoms (Mathew et al., 2017). On the other hand, there are other studies showing that smoking also contributes to the maintenance of feelings of sadness or negative mood (Mathew et al., 2017; Pasco et al., 2008).

Regarding the findings of BMI, obese people had $60 \%$ higher chance to exhibit more depression-related symptoms compared to non-obese individuals. It seems to be well established that obesity, in addition to causing physical damage, may also increase both the chances for psychological problems, and the probability to get anxious and/or depressive (Luppino et al., 2010). Likewise, obese people are often target of discrimination and prejudice. Hence, the stigma towards the obese person can lead to negative perceptions of one's own self and body (Puhl \& Heuer, 2009). This could result in the devaluation of the self-image and self-concept, reducing one's self-esteem and well-being, conversely increasing the sense of social inadequacy, which might well favor the emergence of symptoms related to depression and anxiety among obese people (Almeida, Zanatta, \& Rezende, 2012).

In summary, the proposed objectives to this study allowed to infer that the population living in Aracaju present a high prevalence rate of depression-related symptoms (almost 35\%). Considering that the interviews were conducted at home, it is still possible that part of the sample that showed these symptoms may not have sought assistance at UBS health centers or have been assessed by primary care; something that remains for future investigations.

Some limitations of the present study must be reported. One is that the results of this research may not be unrestrictedly applied to the general population regardless of age, since the representativeness of the sample was restricted to adults, excluding adolescents and elderly, for instance. Another limitation is related to the absence of a clinical instrument for parallel comparisons of BDI data. For example, although the BDI is a reliable screening measure, the clinical interview helps identify false positives that can occur with frequency during diagnostic investigation through self-report scales, as well as allowing the analysis of criterion validity of diagnostic parameters (Streiner, Norman, \& Cairney, 2015).

Finally, we think that an interesting future step could be to replicate this study in populationbased samples from other Brazilian small capitals and municipalities for comparison of explanatory factors and prevalence of depression. Moreover, it is also recommended to carry out further work to stratify the severity levels of depressive disorder, since most of the studies only identify the presence or absence of depression or its symptoms. 



\section{References}

Almeida, S. S., Zanatta, D. P., \& Rezende, F. F. (2012). Imagem corporal, ansiedade e depressão em pacientes obesos submetidos à cirurgia bariátrica. Estudos em Psicologia, 17, 153-160. doi:10.1590/S1413-294X2012000100019

American Psychiatric Association (2013). Diagnostic and statistical manual of mental disorders (DSM-5). Washington DC: American Psychiatric Association.

Andrade, L. H., Wang, Y. P., Andreoni, S., Silveira, C. M., Alexandrino-Silva, C., Siu, E. R., ... Viana, M. C. (2012). Mental Disorders in Megacities: Findings from the São Paulo Megacity Mental Health Survey, Brazil. PloS one, 7(2): e31879. doi:10.1371/journal.pone.0031879

Baker, D. P., Leon, J., Greenaway, E. G. S., Collins, J., \& Movit, M. (2011). The education effect on population health: A reassessment. Population and Development Review, 37(2), 307-332. doi:10.1111/j.1728-4457.2011.00412.x.

Boot, C. R., Koppes, L. L., Van der Bossche, S. N., Anema, J. R., \& Van der Beek, A. J. (2011). Relation between perceived health and sick leave in employees with a chronic illness. Journal of occupational rehabilitation, 21(2), 211-219. doi:10.1007/s10926-010-9273-1

Bortoluzzi, M. C., Kehrig, R. T., Loguercio, A. D., \& Traebert, J. L. (2011). Prevalência e perfil dos usuários de tabaco de população adulta em cidade do Sul do Brasil (Joaçaba, SC). Ciência \& Saúde Coletiva, 16(3), 1953-1959. doi:10.1590/S1413-81232011000300029

Bromet, E., Andrade, L. H., Hwang, I., Sampson, N. A., Alonso, J., Girolamo, G., ... Kessler, R. C., (2011). Cross-national epidemiology of DSM-IV major depressive episode. BMC Medicine, 9(90), 1-16. doi:10.1186/1741-7015-9-90

Coelho, C. L. S., Crippa, J. A. S., Santos, J. L. F., Pinsky, I., Zaleski, M., Caetano, R., \& Coelho, R. L. (2013). Higher prevalence of major depressive symptoms in Brazilians aged 14 and older. Revista Brasileira de Psiquiatria, 35, 142-149. doi:10.1590/1516-4446-2012-0875

Cunha, J. A. (2001). Manual da versão em português das Escalas Beck. São Paulo: Casa do Psicólogo.

De Mello, M. T., Lemos, V. A., Antunes, H. K. M., Bittencourt, L., Santos-Silva, R., \& Tufik, S. (2013). Relationship between physical activity and depression and anxiety symptoms: A population study. Journal of Affective Disorders, 149, 241-246. doi:10.1016/j.jad.2013.01.035

Feinstein, L., Sabates, R., Anderson, T. M., Sorhaindo, A., \& Hammond, C. (2006). What are the effects of education on health? In A review for the OECD Centre for Educational Research and Innovation (CERI), The effects of education on health: Concepts, Evidence and Policy Implications (pp. 171-352). Paris: CERI.

Ferrari, A. J., Somerville, A. J., Baxter, A. J., Norman, R., Patten, S. B., Vos, T., \& Whiteford, H. A. (2013). Global variation in the prevalence and incidence of major depressive disorder: A systematic review of the epidemiological literature. Psychological Medicine, 43, 471-481. doi:10.1017/S0033291712001511

Figueiró, L. R., Bortolon, C. B., Benchaya, M. C., Bisch, N. K., Ferigolo, M., Barros, H. M. T., \& Dantas, D. C. M. (2013). Assessment of changes in nicotine dependence, motivation, and symptoms of anxiety and depression among smokers in the initial process of smoking reduction or cessation: A short-term follow-up study. Trends in Psychiatry and Psychotherapy, 35(3), 212220. doi:10.1590/S2237-60892013000300008

Gonçalves, D. A., Mari, J. J., Bower, P., Gask, L., Dowrick, C., Tófoli, L. F., .. \& Fortes, S. (2014). Brazilian multicentre study of common mental disorders in primary care: Rates and related social and demographic factors. Cadernos de Saúde Pública, 30(3), 623-632. doi:10.1590/0102$311 \mathrm{X} 00158412$

IBGE - Instituto Brasileiro de Geografia e Estatística. (2012). Censo demográfico brasileiro 2010. Rio de Janeiro, IBGE. Retrieved from: https://ww2.ibge.gov.br/home/estatistica/populacao/censo2010/

Jamal, M., Van der Does, W., Cuijpers, P., \& Pennix, B. W. (2012). Association of smoking and nicotine dependence with severity and course of symptoms in patients with depressive or anxiety disorder. Drug Alcohol Dependence, 126, 138-146. doi:10.1016/j.drugalcdep.2012.05.001. 
Kaskow, J. W., Karp, J. F., Whyte, E., Butters, M., Brown, C., Begley, A., ... Reynolds Lii, C. F. (2013). Subsyndromal depression and anxiety in older adults: Health related, functional, cognitive and diagnostic implications. Journal of Psychiatric Research, 47(5), 599-603. doi:10.1016/j.jpsychires.2013.01.017

Katon, W. J. (2011). Epidemiology and treatment of depression in patients with chronic medical illness. Dialogues in Clinical Neuroscience, 13, 7-23. Retrieved from: https://www.ncbi.nlm.nih.gov/pmc/articles/PMC3181964/pdf/DialoguesClinNeurosci-13-7.pdf

Kessler, R. D., \& Bromet, E. J. (2013). The epidemiology of depression across cultures. Annual Review of Public Health, 34, 119-138. doi:10.1146/annurev-pubhealth-031912-114409

Luger, T. M., Suls, J., \& Weg, M. W. W. (2014). How robust is the association between smoking and depression in adults? A meta-analysis using linear mixed-effects models. Addictive Behaviors, 39(10). 1418-1429. doi:10.1016/j.addbeh.2014.05.011

Luppino, F. S., de Wit, L. M., Bouvy, P. F., Stijnen, T., Cuijpers, P., Penninx, B. W., \& Zitman, F. G. (2010). Overweight, obesity, and depression: A systematic review and meta-analysis of longitudinal studies. Archives of General Psychiatry, 67(3), 220-229. doi:10.1001/archgenpsychiatry.2010.2

Martínez, P., Rojas, G., Fritsch, R., Martínez, V., Vohringer, P., \& Castro, A. (2017). Comorbilidad en personas con depresión que consultan en centros de la atención primaria de salud en Santiago, Chile. Revista Médica del Chile, 145, 25-32. doi:10.4067/S0034-98872017000100004

Mathew, A. R., Hogarth, L., Leventhal, A. M., Cook, J. W., \& Hitsman, B. (2017). Cigarette smoking and depression comorbidity: Systematic review and proposed theoretical model. Addiction, 112(3),401-412. doi:10.1111/add.13604

Moreira-Almeida, A., Koenig, H. G., \& Lucchetti, G. (2014). Clinical implications of spirituality to mental health: Review of evidence and practical guidelines. Revista Brasileira de Psiquiatria, 36(2), 176-182. doi:10.1590/1516-4446-2013-1255

Pasco, J. A., Williams, L. J., Jacka, F. N., Ng, F., Henry, M. J., Nicholson, G. C., ... Berk, M. (2008). Tobacco smoking as a risk factor for major depressive disorder: Population-based study. The British Journal of Psychiatry, 193, 322-326. doi:10.1192/bjp.bp.107.046706

Puhl, R. M., \& Heuer, C. A. (2009). The stigma of obesity: A review and update. Obesity, 17(5), 941964. doi:10.1038/oby.2008.636

Salk, R. H., Hyde, J. S., \& Abramson, L. Y. (2017). Gender differences in depression in representative national samples: Meta-analyses of diagnoses and symptoms. Psychological Bulletin, 143, 783822. doi: $10.1037 /$ bul0000102

Santos, E. B., Quintans Junior, L. J., Fraga, B. P., Macieira, J. C., \& Bonjardim, L. R. (2012). Avaliação dos sintomas de ansiedade e depressão em fibromiálgicos. Revista da Escola de Enfermagem da USP, 46(3), 590-596. doi:10.1590/S0080-62342012000300009

Schuch, J. J., Roest, A. M., Nolen, W. A., Penninx, B. W., \& de Jonge, P. (2014). Gender differences in major depressive disorder: Results from the Netherlands study of depression and anxiety. Journal of Affective Disorders, 156, 156-163. doi:10.1016/j.jad.2013.12.011

Silva, M. T., Galvao, T. F., Martins, S. S., \& Pereira, M. G. (2014). Prevalence of depression morbidity among Brazilian adults: A systematic review and meta-analysis. Revista Brasileira de Psiquiatria, 36(3), 262-270. doi:10.1590/1516-4446-2013-1294.

Streiner, D. L., Norman, G. R., \& Cairney, J. (2015). Health measurement scales: A practical guide to their development and use (Fifth Edition). Oxford: Oxford University Press.

Stubbs, B., Vancampfort, D., Veronese, N., Thompson, T., Fornaro, T., Schofield, P. ... Koyanagi, A. (2017). Depression and pain: Primary data and meta-analysis among 237952 people across 47 low- and middle-income countries. Psychological Medicine, 47(16), 2906-2917. doi:10.1017/S0033291717001477

Vianna, M. C., Teixeira, M. G., Beraldi, F., Bassani, I. S., \& Andrade, L. H. (2009). São Paulo Megacity Mental Health Survey - A population-based epidemiological study of psychiatric morbidity in the São Paulo metropolitan area: Aims, design and field implementation. Revista Brasileira de Psiquiatria, 31(4), 375-386. doi:10.1590/S1516-44462009000400016

Vos, T., Allen, C., Arora, M., Barber, R. M., Bhutta, Z. A., Brown, A., ... Murray, C. J. L. (2016). Global, regional, and national incidence, prevalence, and years lived with disability for 310 
diseases and injuries, 1990-2015: A systematic analysis for the Global Burden of Disease Study 2015. Lancet; 388, 1545-1602. doi:10.1016/S0140-6736(16)31678-6.

Wang, Y. P., Andrade, L. H., \& Gorenstein, C. (2005). Validation of the Beck Depression Inventory for a portuguese-speaking Chinese community in Brazil. Brazilian Journal of Medical and Biological Research, 38, 339-408. doi:10.1590/S0100-879X2005000300011

World Health Organization (WHO) (2013). Mental health action plan 2013-2020. Geneva: WHO.

World Health Organization [WHO]. (2017). Depression and other common mental disorders: Global Health Estimates. Geneva: World Health Organization. Retrieved from http://apps.who.int/iris/bitstream/10665/254610/1/WHO-MSD-MER-2017.2-eng.pdf. 